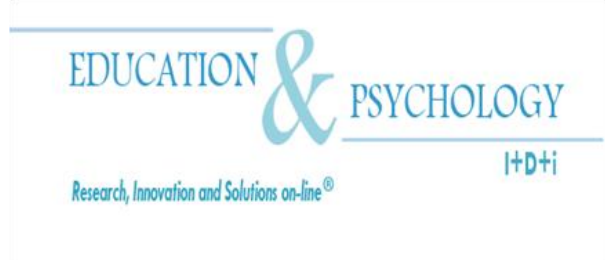

\title{
Cognitive Abilities, Adjustment and Parenting Practices in Preschoolers with Disruptive Conduct Problems
}

\section{Fernández-Parra, A., López-Rubio, S., Mata, S., Calero, M.D., Vives, M.C., Carles, R. and Navarro, E.}

Department of Personality, Assessment and Treatment, University of Granada, Granada

\section{Spain}

Correspondence: Sara Mata Sierra. Department of Personality, Assessment and Treatment, Campus Universitario de la Cartuja s/n, Facultad de Psicología, 18071, Granada. Spain. E-mail: $\underline{\text { saramata@ugr.es }}$ 


\section{Abstract}

Introduction. Conduct problems arising in infancy are one of the main reasons for which parents seek psychological assistance. Although these problems usually begin when the child has started school, in recent years a group of children has been identified who begin to manifest such problems from their earliest infancy and whose prognosis seems to be particularly negative.

Method. The participants in this study were 175 preschoolers aged between 4 and 5 years with and without conduct problems. Learning-related cognitive abilities, attitudes and parenting practices were assessed in all cases.

Results. The results demonstrate differences between the two groups in all the aspects studied here, making it clear that these types of problems have a significant impact on family life and quickly become generalized to different contexts of child functioning.

Discussion and Conclusion. Prescholres with conduct problems have difficulties in mastering certain cognitive abilities and in acquiring attitudes towards learning. The study also highlights the importance of parental strategies for disciplining their children and their expectations regarding their child's capacities.

Keywords: preschoolers, conduct problems, parenting practices, cognitive abilities, socioemotional adjustment.

Received: 05/01/13 Initial acceptance: 06/15/13 Final acceptance: 11/08/13 


\section{Habilidades cognitivas, ajuste y prácticas de crianza en preescolares con problemas de conducta disruptiva}

\section{Resumen}

Introducción. Una de las principales razones por las que los padres solicitan la asistencia psicológica de sus hijos es la existencia de problemas de conducta. Aunque dichos problemas suelen aparecer cuando los niños comienzan la etapa escolar, se ha observado el desarrollo de los mismos desde la infancia temprana en algunos niños, con un pronóstico particularmente negativo.

Método. Los participantes de este estudio fueron 175 preescolares de entre 4 y 5 años, con y sin problemas de conducta. Las variables estudiadas fueron habilidades cognitivas relacionadas con el aprendizaje, actitudes y prácticas de crianza.

Resultados. Los resultados demuestran diferencias significativas entre grupos en todos los aspectos estudiados, haciendo evidente que los problemas de conducta tienen un impacto significativo en la vida familiar y que se generalizan a diferentes contextos del funcionamiento del niño.

Discusión y Conclusiónes. Los preescolares con problemas de conducta presentan dificultades en el dominio de ciertas habilidades cognitivas y en la adquisición de actitudes relacionadas con el aprendizaje. El estudio también señala la importancia de las prácticas de crianza y de las expectativas de los padres sobre las capacidades de sus hijos.

Palabras Clave: preescolares, problemas de conducta, prácticas de crianza, habilidades cognitivas, ajuste socio-emocional 


\section{Introduction}

Conduct problems at school are an increasingly frequent phenomenon that has become the focus of great concern. Several studies (Brownline, Beitchman, Escobar, Young, Atkinson, Johnson et al., 2004; Juvonen \& Ho, 2008) have attempted to identify the causes with a view to remediating this problem and averting its negative impact on child development. From their first years at school, some children present problems of inappropriate classroom behavior and have difficulties making and maintaining friendships with their classmates (Morgan, Farkas \& Wu, 2009). Moreover, these difficulties do not seem to diminish or disappear over the years, but on the contrary seem to persist and even increase to the point where they can constitute serious antisocial disorders (Bilancia, \& Rescorla, 2010).

In spite of the interest in factors associated with the appearance and persistence of conduct problems, previous studies have centered mainly on school-age children, since disruptive behavior in preschool children has often been considered developmentally normal (Dodge, Coie \& Lynam, 2006; Wakschlag, Leventhal, Briggs-Gowan, Danis, Keenan, Hill et al., 2005). However, when this type of conduct extends beyond the earliest years it becomes a problem affecting all aspects of the child's day-to-day life (Chacko, Wakschlag, Hill, Danis \& Espy, 2009). Moreover, the early manifestation of disruptive conduct may be viewed as a fairly reliable indicator of the appearance of more serious conduct problems requiring specialized attention (Campbell, Shaw \& Gilliom, 2000). In this connection, earlier studies (Lahey, Van Hulle, Rathouz, Rodgers, D'onofrio \& Waldman, 2009) have found that oppositional-defiant and attention deficit-hyperactive behaviors between the ages of 4 and 7 years were predictive of behavior problems between 8 and 13 years of age. Research by Harvey, Youngwirth, Thakar and Errazuriz (2009) has indicated that a large proportion of children who display conduct problems at 3 years of age met the diagnostic criteria for ADHD, ODD or both 3 years later.

This view is supported by Fergusson, Horwood and Ridder (2005), who indicate that children presenting conduct problems at 7 to 9 years of age have a greater risk of antisocial personality disorders in the early years of adulthood (21-25 years old). Longitudinal studies support this thesis, and emphasize that the stable nature of these conduct problems is particularly notable in preschoolers who display them in different settings (Egeland, Pianta \& Ogawa, 1996). 
In addition, such children have a greater risk of presenting other difficulties such as poor academic achievement, low work output, problematic sexual relations, problematic partner relations, substance abuse, anxiety and depressive disorders and suicide acts. Along the same lines, a study by Moffit (as cited in Rutter, Kim-Cohen \& Maughan, 2006) has established that some of these children present long-term problems characterized by social isolation, avoidance of close relationships and a tendency to suffer from anxiety and depression.

Several studies, including those of Campbell (2006) and Wakschlag et al. (2005) have identified three key areas of functioning in preschoolers that predict the development of conduct problems in the early years: skills of behavioral control, emotional modulation and social orientation act. These findings underscore the need to identify those preschoolers at risk of presenting conduct problems (Karreman, van Tuijl, van Aken \& Dekovic, 2009).

The development of conduct problems during infancy does not result from a single etiological factor but rather from a series of risk and protective factors which may be biological, psychological or social in nature (Trentacosta, Hyde, Shaw, Dishion, Gardner \& Wilson, 2008). One such risk factor mentioned repeatedly in specialized studies is parenting practices, in the widest sense of the term (Webster-Stratton \& Taylor, 2001). Accordingly, in recent years researchers have stressed the importance of studying the behavior of the parents in relation to their children, and the manner in which the children develop from both a socioemotional and a behavioral point of view (Hardaway, Wilson, Shaw, \& Dishion, 2012).

Different authors have established associations between the type of practices used by parents to correct and control inappropriate types of conduct in their children (disciplinary practices) and their repercussions on the child's adjustment (Capaldi, Pears, Kerr \& Owen, 2007; Del Vecchio \& O'Leary, 2008). These studies highlight the negative consequences on both emotional and behavioral aspects deriving from disciplinary practices characterized by the frequent use of physical punishment (Baumrind, 1971; Gámez-Guadix, Straus, Carrobles, Muñoz-Rivas \& Almendros, 2010; Larzelere \& Kuhn, 2005). In this connection, Patterson (1982) developed a theory on the origin and persistence of conduct problems in children based on the study of family interaction patterns. This explanatory model emphasizes disciplinary practices which occur in the family context, and claims that antisocial conduct is initiated in the family owing to inappropriate parenting practices. Although most children substi- 
tute this type of conduct for other more appropriate behaviors as they grow older, certain conditions appear to increase the likelihood that antisocial behavior will persist over time. According to Patterson (2002), a subtle learning process takes place characterized by negative reinforcement, whereby the child acquires manipulative types of conduct in his or her relationships with other members of the family. From this perspective, a consideration of disciplinary practices within the family might offer ways to impede or block the coercive process.

A further aspect which a few studies have analyzed is the role of family expectations for the child's academic performance. This variable has been found to be an important predictor of the child's academic success (Neuenschwander, Vida, Garrett \& Eccles, 2007; Rutchick, Smyth, Lopoo \& Dusek, 2009). In turn, the formation of such expectations is conditioned by variables such as the family's socioeconomic level and the parents' educational level (Solís, Díaz, del Carpio, Esquivel, Acosta \& de Jesús, 2007). However, parental expectations seem not only to affect the child's academic performance but also to have a significant influence on the parents' socialization objectives and the development of their children (Rubin, Hemphill, Chen, Hastings, Sanson, LoCoco et al., 2006). A further finding is that disproportionate expectations on the part of the parents are associated with situations of child maltreatment (Stith, Liu, Davies, Boykin, Alder, Harris et al., 2009). Despite these findings, few studies have related parental expectations to the appearance of conduct problems, and these studies have viewed parental expectations as a variable that mediates in the relation between these problems and other parental variables (Gutermuth-Anthony, Anthony, Glanville, Naiman, Waanders \& Shaffer, 2005).

In contrast, the comorbidity between aggressive conduct and low academic achievement in adolescents has been clearly documented (Rogevich \& Perin, 2008). A review of the literature emphasizes the relationship between preschoolers' conduct disorders and serious conduct problems on the one hand, and deficiencies in academic skills on the other (AlHendawi, 2013). Low academic performance is also a risk factor for a variety of negative long-term outcomes, including social and conduct problems, high rates of school drop-out, and unemployment (Smart, Prior, Sanson \& Oberklaid, 2005). Nevertheless, studies which have attempted to relate the two variables, although few, are sufficient to confirm that academic difficulties begin to appear in children with conduct problems from their first years at school (McClelland, Morrison \& Holmes, 2000). Moreover, several studies have concurred that a number of characteristics such as self-regulation, working memory, cognitive flexibility 
and intrinsic motivation are important factors in efforts to achieve suitable levels of academic performance from the earliest years of education (Oudeyer, Kaplan y Hafner, 2007). Calero, Carles, Mata and Navarro (2010) has documented significant differences in the dimensions noted above between preschoolers with high and low levels of school performance, along with persistence in problem-solving related to school tasks. Higher-achieving children scored better in all dimensions than their lower-achieving peers.

A negative relationship has also been demonstrated between self-control and the subsequent development of externalizing problems, which may appear as early as the end of the first year of the child's life, but become more evident from age 3 years (Trosper, Buzzella, Bennett \& Ehrenreich, 2009). Some researchers have recommended additional efforts to shed light on the connection between externalizing problems and parenting practices (Kochanska, Barry, Aksan \& Boldt, 2008). Although the association between deficient self-control and conduct problems is well documented, self-control also seems to be involved in parents' behaviors towards their children during parenting and education (Olson, Sameroff, Kerr, Lopez \& Wellman, 2005). Interaction between the two variables has been reported, and some authors have suggested that negative parenting practices are associated with the appearance of conduct problems only in children with a low capacity for self-control (Bradley \& Corwyn, 2008; Lengua, 2006).

In view of the stable nature of conduct problems that appear early in the child's life and their repercussions at different levels, the early detection of conduct problems early in life should be a primary objective both in the educational system and in the family context. For this approach to be effective, it is essential to determine the factors involved in both the origin and subsequent persistence of and increase in disruptive conduct in children (Juliano, Werner $\&$ Cassidy, 2006). These measures are likely to require consideration of the parents' role in the appearance of this type of problem, in the light of the findings of earlier work reviewed above.

\section{Objective}

For all these reasons, the main objective of this study was to determine the relationship between disruptive and hyperactive/attention-deficit conduct in preschoolers and their adjustment on a personal, family, social and school level. In addition, this study was designed to determine the relationship between these conducts and parenting practices. Specifically, we 
wished to establish whether preschoolers with conduct problems differ from their peers without conduct problems in the following areas: 1) parenting practices, 2) the emotional, social, school and behavioral adjustment of these children both in the family context and at school, 3) the impact of conduct problems on the family, 4) their cognitive performance in the preschool curriculum tasks, and 5) their attitudes towards learning. A final aim was to identify which of the variables of interest discriminate most effectively between preschoolers with and without conduct problems.

\section{Method}

\section{Participants}

The participants in this study were 175 preschoolers aged between 4 and 5 years $\left(M_{\text {months }}=55.25, S D=3.92\right)$ who attended 20 different public-sector schools in the city of Granada, Spain, and the surrounding metropolitan area. The parents of all children in the age range of this study were also asked to participate, and the teachers of all children included in the study also took part $(n=26)$. All parents who agreed to participate $(n=350)$ were asked to complete the evaluation instruments. After the data were obtained, the children whose score was indicative of risk (borderline or abnormal, based on cut-off values determined specifically for this study) were enrolled. The borderline score for disruptive behavior was 3 , and scores between 4 and 10 were considered abnormal. The borderline score for hyperactive/attention-deficit conduct problems was 6 , and scores between 7 and 10 were considered abnormal, based on previous measurements with the parents' version of the Strengths and Difficulties Questionnaire (SDQ) (Goodman, 1997). This case group, called the conduct problems group, consisted of 77 children $\left(M_{\text {months }}=55.23, S D=4.24\right)$. A second group of 98 children with normal scores on the relevant SDQ scales also took part on the study $\left(M_{\text {months }}=\right.$ $55.33, S D=3.65)$. The gender distribution was 42 girls, 35 boys in the case group and 55 girls, 43 boys in the control group.

With respect to the parents, only the mother completed the assessment instruments for $73.8 \%$ of the children in the case group, only the father for $13.4 \%$ of these children, both parents together for $11.6 \%$, and another relative for the remaining $1.2 \%$. Regarding the parents' educational level, $43.3 \%$ of the mothers had completed secondary education, and $31.2 \%$ had higher education qualifications, $20.4 \%$ had completed primary education and $5.1 \%$ had no 
education. Among the fathers, $47.9 \%$ had completed secondary education, $27.2 \%$ had a higher education qualification, $20.7 \%$ had primary education and $4.3 \%$ had no formal education.

Concerning employment status, $46 \%$ of the mothers were housewives, $27.3 \%$ were employed in unskilled work, $14.3 \%$ were employed in skilled work and $12.4 \%$ were employed in semi-specialized jobs (administration, trade, services, skilled labor). With regard to the fathers, $45.3 \%$ were employed in semi-specialized jobs, $24.8 \%$ were employed in unskilled work, $18.2 \%$ were unemployed and $11.7 \%$ worked in the highly specialized sector (health, education, business or technology).

\section{Instruments}

Strengths and Difficulties Questionnaire (SDQ) (Goodman, 1997) is a brief screening questionnaire based on the diagnostic criteria used in the CIE-10. The questionnaire assesses the conduct of children between 4 and 16 years of age according to 25 desirable or undesirable characteristics. For each item, the participant uses a three-point Likert scale $(0=$ never, 1 $=$ sometimes, 2 = always) to indicates the extent to which the attribute in question is applicable to the child. The 25 items are divided into 5 scales generating scores for emotional symptoms, conduct problems, hyperactivity, peer problems and prosocial behavior. The first four scales are summed to obtain an overall score for difficulties. In this study, the Spanish version for parents (SDQ-P 4-16) and teachers (SDQ-T 4-16) were used. Internal consistency of the questionnaire is satisfactory, with Cronbach's alpha is between .73 and .80 for the different scores and informants (Goodman, 2001).

Escala Breve de Comportamientos para Madres y Padres de Niños Pequeños [Short Behavior Scale for Mothers and Fathers of Small Children (BSMF)] (Solís, Díaz, Medina \& Barranco, 2002; Solís, 2007) assesses parental goal-directed behaviors used by parents to fulfill their maternal or paternal responsibilities. The scale consists of three empirically derived subscales and factor analyses. The short version used in this study consists of 32 items, of which 11 refer to parental expectations ("I believe my child should be capable of using a spoon without spilling food"), 10 refer to disciplinary practices ("If my child cries after I have put him/her to bed, I scold him/her"), and 11 to parenting ("I play make-believe games with my child"). Parents assess their behavior on a 4-point Likert scale in which high expectation scores are associated with expectations that surpass the child's abilities, high scores in disciplinary practices are associated with frequent use of physical and verbal punishment, and high 
parenting scores reflect frequent use of positive parenting practices. Analysis of the psychometric properties of the scale shows an internal consistency between .80 and .95 , and analysis of the correlations between the long and short versions indicates that the correlations are significant for expectations $(r=.84)$, discipline $(r=.79)$ and child-rearing practices $(r=.86)$ (Solís, Díaz, Cortés, Patiño, Pérez \& Robles, 2005).

Inventario de Experiencia Familiar [Family Experiences Inventory, FEI] (Bauermeister, Matos \& Reina, 1999) consists of a series of scales designed to assess how the child's behaviour in different settings affects parents' feelings and cognitions towards the child, the family's social life, household expenses, relations with siblings and relations between spouses or partners. Featuring 43 items distributed unequally across the scales. Parents indicate the relative frequencies of the items on a scale from 0 (never or hardly ever) to 3 (very frequently). Items are grouped in the following scales: impact on social life, positive impact on the parents' thoughts and cognitions, expectations about the child's future, impact on relations with the school, financial burden and impact on partner relations. High scores indicate a negative impact in each area except in the scale for positive impact on cognitions, in which higher scores reflect a more positive impact. Analysis of the psychometric properties indicate an internal consistency between .63 and .89 in samples of Spanish children (Bauermeister \& Cumba, 2008). Concurrent validity was verified by examining the degree of association between IEF scores on the Escala de Prácticas Inadecuadas del Inventario de Prácticas de Crianza [Scale of Inappropriate Practices of Parenting Practices Inventory] (Barkley, Murphy \& Bauermeister, 1998), the Escala de Destrezas Sociales [Social Skills Scale] (Gresham \& Elliot, 1990) and the Escalas del TDAH y del TOD [Scales of ADHD and ODD] (Barkley et al., 1998). All correlations were statistically significant $(p<.05$, two-tailed tests).

Kaufman's Brief Intelligence Test (K-BIT) (Kaufman \& Kaufman, 1994) is an instrument designed to measure verbal and non-verbal intelligence in persons 4 to 90 years old. The test consists of two subtests titled 'Vocabulary' and 'Matrices'. Typical age-related scores are provided for each subtest, as well as a global composite IQ. Reliability studies indicate an internal consistency of .85 for the 'Vocabulary' subtest, .86 for 'Matrices' and .98 for composite IQ. Both subtests have demonstrated adequate stability with time in test/re-test analyses. Validity studies show that the composite K-BIT IQ has a correlation of .80 with the global WISC-R IQ and .75 with the WAIS-R. 
Application of Cognitive Functions Scale (ACFS) (Lidz \& Jepsen, 2003) measures the application of learning strategies and cognitive processes in typical tasks of the primary education curriculum. Designed for children from 3 to 5 years old, the instrument consists of six subtests: classification, auditory memory, visual memory, pattern sequences, perspective taking (ability to understand and put himself or herself in the place of the other person) and verbal planning. Scores on this scale are quantitative, not normative (raw scores). Application follows the pretest-mediation-posttest format, enabling researchers to calculate learning potential in the post-mediation task. The ACFS includes the Behavior Observation Rating Scale (BORS), which evaluates seven attitudes of the child in relation to learning: self-regulation, persistence, frustration tolerance, flexibility, motivation, interactivity and responsivity. Several studies of the transfer scores have substantiated the test's reliability, construct validity and discriminant validity (Calero, Márquez, Robles \& de la Osa, 2009). In the present study, only the ACFS and BORS pretest scores were used, in order to assess the child's performance on each subtest specifically.

Educational and Sociodemographic Data Index records information about age, educational level and profession for parents and, age, number of years at school, participation in free time activities, friendships, ranking in relation to siblings, and health problems for children.

\section{Procedure}

The study was submitted for approval to the University of Granada Ethics Commission for human research. Subsequently, 20 schools in the City of Granada and surrounding metropolitan area were identified at random and contact was established to request their cooperation. Once the schools had been selected, parents were asked to give their informed consent to participate in the study and to complete the SDQ-P to assess their children in different areas. A total of 406 children were assessed, and their results for the task criterion (Goodman, 1997) were used to divide the sample into children who obtained abnormal scores for externalizing problems (indicating conduct problems and hyperactivity/impulsiveness) and children who obtained normal scores.

Data were collected in the course of face-to-face meetings with the parents, during which they completed the tasks. Teachers who had also agreed to participate completed the SDQ-T 4-16 assessment instrument. Help was available to both parents and teachers through- 
out the assessment process. Children were evaluated individually in a room separate from the classroom, in two sessions lasting 20 to 30 minutes each.

To assess the children's academic performance, teachers assessed the academic performance of each child in six curricular areas: mathematics (knowledge of numbers and simple arithmetic), oral/written expression (pre-reading and writing skills and oral comprehension and expression through simple tasks such as stories, songs, etc.), personal identity and autonomy (body image and personal adjustment), physical and social medium (knowledge of physical and cultural environment in order to understand the reality), corporal expression and artistic expression (psychomotor skills and artistic expression). Scores were allocated as follows: (1) low performance, (2) average performance and (3) high performance, with a total score range from 6 to 18. This register has been shown to have a Cronbach Alpha reliability of .94 for the complete set of items.

\section{Desing and data analysis}

The study used a quasi-experimental design with two groups (with and without disruptive conduct). All data were analyzed with version 18.0 of the SPSS software. Specifically, Student's t-tests (independent samples) were carried out for analysing quantitative variables, while Chi-squared tests were developed for cualitative variables. Spearman's rank correlation coefficient and discriminant function analysis were also employed.

\section{Results}

There were significant differences between the two groups in all the parenting practice variables we investigated, namely expectations, discipline and child-rearing practices. As shown in Table 1, the parents of children with conduct problems had reduced expectations for the things they expected their children to be able to do according to their age. These parents also used physical and verbal punishment more frequently to correct inappropriate behavior in their children. Parents of the children without conduct problems cared for their children more appropriately and provided them with stimulating experiences more frequently.

The impact of the child's behavior on different aspects of family life was also analyzed. The results in Table 1 indicate that parents of preschoolers with conduct problems perceived that their children had a more negative impact on their social life and represented a 
heavier financial burden than parents of preschoolers without conduct problems. In both cases the effect size was moderately large.

Table 1. Comparison of Children without ) and with Conduct Problems with Respect to their Parents' Practices and Behaviors (BSMF) and the Child's Impact on Family Life (IFE)

\begin{tabular}{|c|c|c|c|c|}
\hline Scales & $\begin{array}{c}\text { Non-problems } \\
\text { Group } \\
M(S D)\end{array}$ & $\begin{array}{l}\text { Problems Group } \\
\qquad M(S D)\end{array}$ & $t$ & $d$ \\
\hline$B S M F$ & & & & \\
\hline Expectations & $39.69(5.19)$ & $36.12(7.97)$ & $3.58 * * *$ & 0.53 \\
\hline Discipline & $13.77(3.69)$ & $15.58(4.31)$ & $3.01 * *$ & 0.45 \\
\hline Parenting & $33.57(5.26)$ & $31.95(6.44)$ & 1.83 & 0.27 \\
\hline FEI & & & & \\
\hline Positive impact & & & & \\
\hline $\begin{array}{l}\text { on thoughts } \\
\text { Social impact }\end{array}$ & $\begin{array}{c}26.05(4.26) \\
1.46(2.54)\end{array}$ & $\begin{array}{c}25.76(6.06) \\
3.42(3.62)\end{array}$ & $\begin{array}{c}0.37 \\
4.20 * * *\end{array}$ & $\begin{array}{l}0.05 \\
0.62\end{array}$ \\
\hline Impact at school & $6.48(2.25)$ & $7.00(3.10)$ & 1.29 & 0.19 \\
\hline Financial burden & $0.88(2.08)$ & $1.60(2.72)$ & $1.98 *$ & 0.29 \\
\hline $\begin{array}{l}\text { Impact on } \\
\text { partner relations }\end{array}$ & $7.70(2.60)$ & $8.04(4.26)$ & 0.64 & 0.09 \\
\hline
\end{tabular}

Table 2 shows the results for difficulties associated with parent-reported conduct problems in the family and school context. The frequency of emotional symptoms and problems in relations with peers was significantly higher in the problem group. Differences were also found in the frequency of manifestations of prosocial behavior; in this case the problem group had fewer manifestations of prosocial behavior than their peers without problems.

Teacher-reported conduct problems were generally similar to parent-reported problems, and scores for the problem group were again significantly higher than in the nonproblems group for conduct problems and hyperactivity/attention deficit. These two variables were used as the criteria for assigning children to the problem or non-problems group according to the parents' assessment. Again, prosocial behavior was reported more frequently in the non-problems group than the problem group. The effect size was large for the parent-reported variables, and small for the teacher-reported variables. 
Table 2.Differences between Children without and with Conduct Problems in Difficulties Reported by Parents (SDQ-P) and Teachers (SDQ-T)

\begin{tabular}{|c|c|c|c|c|}
\hline & $\begin{array}{c}\text { Non-problems } \\
\text { Group }\end{array}$ & $\begin{array}{l}\text { Problems } \\
\text { Group }\end{array}$ & & \\
\hline Scales & $M(S D)$ & $M(S D)$ & $t$ & $d$ \\
\hline \multicolumn{5}{|l|}{$S D Q-P$} \\
\hline Emotional symptoms & $1.29(1.28)$ & $2.70(1.97)$ & $5.73 * * *$ & 0.84 \\
\hline Conduct problems & $1.02(0.80)$ & $4.40(1.58)$ & $18.38 * * *$ & 2.69 \\
\hline Hyperactivity & $3.39(2.47)$ & $5.42(2.04)$ & $5.81 * * *$ & 0.90 \\
\hline Peer problems & $1.27(1.38)$ & $2.45(1.78)$ & $4.97 * * *$ & 0.74 \\
\hline Prosocial behavior & $8.50(1.66)$ & $7.30(1.71)$ & $4.68 * * *$ & 0.71 \\
\hline \multicolumn{5}{|l|}{$S D Q-T$} \\
\hline Emotional symptoms & $1.37(1.74)$ & $1.31(1.82)$ & 0.21 & - \\
\hline Conduct problems & $1.34(1.97)$ & $2.31(2.42)$ & $2.94 * *$ & 0.43 \\
\hline Hyperactvity & $2.98(2.92)$ & $4.16(2.75)$ & $2.71 * *$ & 0.41 \\
\hline Peer problems & $1.52(1.60)$ & $1.60(1.57)$ & 0.32 & - \\
\hline Prosocial behavior & $7.14(2.49)$ & $6.38(2.30)$ & $2.09 *$ & 0.31 \\
\hline
\end{tabular}

We also attempted to determine whether disruptive conduct and/or hyperactivity/attention deficit assessed by the parents was related with these and other types of problem as assessed by the teachers. Disruptive conduct by children at home showed a significant positive correlation with disruptive conduct at school $(r=.23, p<.05)$. Hyperactive/attention deficit-type conduct assessed by the parents showed a positive correlation with this type of behavior assessed by the teachers $(r=.28, p<.01)$, and a negative correlation with manifestations of prosocial behavior in the classroom $(r=-.22, p<.05)$.

Table 3 shows results of the analysis of the two groups' performance in a series of structured tasks in the ACFS as well as their attitudes towards learning. The scores for performance on tasks requiring the use of auditory memory were significantly lower in the problem group than the non-problems group. Significant differences were also found in perspective taking. Again, the problem group obtained lower scores than the non-problems group. With regard to self-regulation while carrying out a task, the problem group had significantly greater difficulties than the non problems group. 
Table 3. Differences between Children without and with Conduct Problems in Scores on the ACFS and the BORS

\begin{tabular}{|c|c|c|c|c|}
\hline & $\begin{array}{l}\text { Non-problems } \\
\text { Group }\end{array}$ & Problems Group & & \\
\hline Scales & $M(S D)$ & $M(S D)$ & $t$ & $d$ \\
\hline \multicolumn{5}{|l|}{$A C F S$} \\
\hline Classification & $4.64(2.48)$ & $4.60(2.80)$ & 0.11 & - \\
\hline Auditory memory & $3.55(2.96)$ & $2.57(2.40)$ & $2.36 * *$ & 0.36 \\
\hline Visual memory & $5.97(1.77)$ & $5.75(2.11)$ & 0.73 & - \\
\hline Pattern sequences & $9.12(4.89)$ & $8.66(4.22)$ & 0.65 & - \\
\hline Perspective taking & $11.15(2.81)$ & $10.01(2.88)$ & $2.63 * *$ & 0.40 \\
\hline Verbal planning & $3.71(3.50)$ & $3.66(3.53)$ & 0.10 & - \\
\hline \multicolumn{5}{|l|}{ BORS } \\
\hline Self-regulation & $10.80(2.08)$ & $10.14(2.17)$ & $2.02 *$ & 0.31 \\
\hline Persistence & $11.22(1.68)$ & $11.06(1.47)$ & 0.66 & - \\
\hline Frustration tolerance & $11.42(1.70)$ & $11.23(1.53)$ & 0.74 & - \\
\hline Flexibility & $7.41(2.82)$ & $7.10(2.94)$ & 0.69 & - \\
\hline Motivation & $8.82(2.32)$ & $8.45(2.48)$ & 0.99 & - \\
\hline Interactivity & $7.43(4.15)$ & $7.52(3.68)$ & 0.15 & - \\
\hline Responsivity & $8.26(2.63)$ & $7.96(2.74)$ & 0.72 & - \\
\hline
\end{tabular}

When we compared the K-BIT measure of verbal and non-verbal intelligence and teacher-assessed academic performance in the two groups, our analysis did not reveal any significant differences.

An additional aim of this study was to determine the discriminating value of the several variables in which significant inter-group differences were found (the five IFE scales, the three BSMF scales, the ACFS subtests and dimensions assessed by the BORS). An exploratory stepwise discriminant function analysis (Table 4) yielded an eigenvalue of .266 and canonical correlation of .458 (Wilks' lambda $=.790, X^{2}=40.343, p<.0001$ ). The classification results indicate correct grouping in $70.9 \%$ of the original assignations $(64.9 \%$ in the problem group and $75.5 \%$ in the non-problems group). The variables which best discriminated group assignation are impact of the child on family social life, followed by parental expectations. 
Table 4. Discriminant Function Analysis

\begin{tabular}{|c|c|c|c|c|c|c|}
\hline & Variable & Correlation $^{\mathrm{a}}$ & $\begin{array}{c}F \\
(1,173)\end{array}$ & $\begin{array}{c}\text { Wilks' } \\
\text { lambda }\end{array}$ & $\begin{array}{c}\text { Non-problems } \\
\text { Group } \\
M(S D)\end{array}$ & $\begin{array}{c}\text { Problems } \\
\text { Group } \\
M(S D)\end{array}$ \\
\hline Model 1 & Social impact & .653 & $17.61 *$ & .908 & $1.46(2.54)$ & $3.42(3.62)$ \\
\hline Model 2 & $\begin{array}{l}\text { Social } \\
\text { impact + par- } \\
\text { ents' expecta- } \\
\text { tions }\end{array}$ & .598 & $12.81^{*}$ & .931 & $39.69(5.19)$ & $36.12(7.97)$ \\
\hline Model 3 & $\begin{array}{l}\text { Social impact } \\
+ \text { Parents' } \\
\text { expectations + } \\
\text { Auditory } \\
\text { memory }\end{array}$ & .379 & $5.55^{*}$ & .969 & $3.55(2.96)$ & $2.57(2.40)$ \\
\hline Model 4 & $\begin{array}{l}\text { Social impact } \\
+ \text { Parents' } \\
\text { expectations + } \\
\text { Auditory } \\
\text { memory + } \\
\text { Perspective } \\
\text { taking }\end{array}$ & .383 & $6.92 *$ & .961 & $11.15(2.81)$ & $10.01(2.88)$ \\
\hline
\end{tabular}

Note.

${ }^{\mathrm{a}}$ Function centroids: Problem group: -.579 ; Control group: .455

$* p<.001$

\section{Discussion and Conclusions}

As stated above, this study aimed to determine the differences between a group of preschoolers with conduct problems and a group without problems in cognitive abilities and attitudes toward learning (in the primary education curriculum), and also in their exposure to different parenting practices. A second aim was to establish whether children with and without conduct problems differed in their adjustment on the family and school and levels. Thirdly, the study set out to determine whether conduct problems during the early years have a significant impact on family life, and to identify which of the variables studied here best discriminate between children with and without conduct problems.

The absence of inter-group differences in the parents' or children's sociodemographic variables indicates that the two groups were homogenous with regard to these variables. Traditionally, earlier studies have highlighted aspects such as the family's socioeconomic status as a risk factor for the development of conduct problems (e.g. Webster-Stratton \& Taylor, 2001). Specifically, poverty has been associated with a significant increase in the likelihood of behavioral alterations in the children. The fact that differences in socioeconomic variables 
were not found in this study reflects the parents' middle-class status. In our sample, few parents had a low educational level and were unemployed. For unemployed parents, the associated stress may have been counteracted by their high educational level, and a parent's low level of education may have been similarly counteracted by employment. This would be in consonance with research that has proposed "cumulative risk" as an explanatory factor in the development of conduct problems (Trentacosta, et al., 2008). According to these studies, the greater number of risk factors, the higher the likelihood that the child will develop psychological problems. A socioeconomic "high-risk" environment (e.g. the combination of low educational level and unemployment) did not seem to occur in the present study. Clearly, this does not mean that the family's socioeconomic level was a relevant variable in the study of conduct problems, but rather that this variable could not be analyzed here.

Turning to the influence of parenting practices on young children's conduct problems, parents' expectations in the problem group were significantly lower than in non-problems group parents. This intriguing result merits careful consideration. Several studies have related unrealistic and disproportionate parental expectations with situations of child maltreatment (for a review, see Stith et al., 2009) and low academic performance (Neuenschwander et al., 2007; Rutchick et al., 2009). However, in this study it was possible to establish that when parents expect their children to acquire fewer capacities than they are actually capable of by a certain age, there is a greater likelihood that the children will develop behavioral difficulties. A possible explanation for this finding is that parents who believe that certain child behaviors are acquired in later stages of development act more permissively with regard to their children's conduct problems. However, in the light of the differences between groups in disciplinary practices - problem group parents used physical and verbal punishment more frequently to correct their children's behavior - this explanation seems implausible. In contrast, our results are in consonance with Baumrind's finding (1971) that parents with an authoritative style as well as those with a permissive style both had unrealistic expectations regarding their children's development. The parents described by Baumrind is essentially demanded less of their children, a fact which was reflected in their disciplinary practices, expression of affect and efforts to inculcate their children with a sense of responsibility. Further studies are needed to identify the variables which may mediate between low parental expectations and the use of punitive disciplinary practices. 
Previous research has established that disciplinary practices characterized by more frequent use of physical punishment have negative consequences for the child on emotional, behavioral, academic and social levels in the short, medium and long term (Capaldi et al., 2007; Del Vecchio \& O'Leary, 2008). The present study shows that children with conduct problems had received more punitive correction to control their conduct than their peers with no conduct problems. This finding confirms earlier reports that have dealt with the influence of parents' punitive measures (Gámez-Guadix et al., 2010).

With regard to the impact of a child with conduct problems on social and financial aspects of family life, our analysis illustrates a wide range of repercussions affecting not only the child's but also of the family's adjustment. This impact can be viewed as an index of the level of stress experienced by parents when raising small children with conduct problems. According to Patterson's theoretical model (1982, 2002), parental stress will affect the difficulties experienced by children with conduct problems. The resulting cycle of negative interactions that may be created between parents and children, if sustained for prolonged periods, may generalize into an ever wider range of situations and become a complex and intractable problem for both parties.

Our data analysis disclosed no discrepancies between parents and teachers in the information they provided about preschoolers' conduct. This indicates that the problems we studied are not limited to the family or school context, and therefore implies a higher risk for the preschoolers' social adjustment (Larzelere \& Kuhn, 2005). Children who begin to have conduct problems at home at an early age also tend to have similar problems at school. This is an important finding since longitudinal studies have reported that conduct problems are more likely to persist or become worse with time in young children who have conduct problems in different contexts (Egeland et al., 1996).

Our findings identified differences in cognitive skills between the two groups specifically for auditory memory and perspective taking. In addition, children with conduct problems experienced greater difficulty with self-regulation than the non-problems group. These three deficits are consistent with the presence of disruptive behavior or externalizing types of conduct. Previous studies have shown a negative relationship between self-control and the subsequent development of externalizing problems (Eisenberg, Zhou, Spinrad, Valiente, Fabes \& Liew, 2005). Because self-regulation requires sustained attention and the inhibition 
of impulsive responses, all cognitive and behavioral capacities related to this variable are likely to be altered in children with conduct problems. Our results in this regard are in line with earlier findings (Bradley \& Corwyn, 2008; Lengua, 2006) that negative parenting practices may be related to the development of conduct problems only in children with a low capacity for self-regulation.

The results of the discriminant analysis show that the variable which discriminated best between groups was the child's impact on family social life, understood as the stress experienced by parents when they are with the child in social situations. Other variables found to discriminate well between groups were parental expectations and performance on tasks requiring auditory memory and perspective-taking. Together, these variables correctly assigned $70.9 \%$ of the children in the present study to the problem or non-problems group. This finding is consistent with earlier studies that highlighted the importance of reciprocal and bidirectional relationships between parents and children. According to these reports, not only do the parents influence the children through their expectations, but children also have a direct influence on their parents' lives through their conduct, by affecting social and financial spheres (Bradley \& Corwyn, 2008; Lengua, 2006).

The chief limitation of this study is the sample size, which was determined by the inclusion criteria and the focus on disruptive conduct problems. A further limiting factor was the geographical area covered by the study (the City of Granada and surrounding metropolitan area), since increasing the sample size would have required increasing the geographical setting. On the other hand, the chief strength of the study is the fact that the data were provided by different adult informants as well as by the preschoolers themselves.

In conclusion, the present study highlights the importance of parental strategies for disciplining their children and their expectations regarding their child's capacities, both of which play a decisive role in the early development of disruptive and hyperactive/attentiondeficit conduct problems. In addition, our study shows that preschoolers who begin to present these types of difficulties in the home context also present them in other contexts such as the school. Moreover, these conduct problems in young children have a considerable negative impact on the family, such that in the short or medium term family dynamics may be altered and the relationships between parents and their children may deteriorate. In the school context, our findings show that children with conduct problems also have difficulties in mastering 
certain cognitive abilities and in acquiring attitudes towards learning which are essential for adequate academic performance. Conduct problems are also accompanied by problems in their relationships with peers, since prosocial types of behavior, essential for optimal adjustment in the school environment, are less frequent in children with than without such problems. These difficulties can all be assumed to affect the child to some extent on an emotional level. Indeed, the present study shows that preschoolers with externalizing or disruptive conduct problems also have greater emotional problems.

There is thus an evident need to control, to extent this is possible, the risk factors that have been repeatedly identified in the literature (including this study) as instrumental in the development of conduct problems in young children. In addition, there is a clear need for early detection and intervention with families before conduct problems become stable patterns of behavior that can lead to more serious consequences. The fact that the negative consequences of conduct problems are already apparent by the time the child reaches 4 years of age should alert us to the importance of focusing on prevention on every level as a priority objective for all those who play a role in child development.

\section{Acknowledgements}

This research was supported by the Andalusia Regional Government (Junta de Andalucía) through Proyecto de Excelencia no. 07-HUM-02535. We thank the Granada Provincial Delegation of the Education Council of the Andalusia Regional Government for facilitating access to children and teachers at public preschools, and express our appreciation to all the children, parents and teachers who participated in this research. We thank K. Shashok for translating parts of the manuscript into English and for revising the translation of the rest of the manuscript. 


\section{References}

Al-Hendawi, M. (2013). Temperament, school adjustment, and academic achievement: existing research and future directions. Educational Review, 65, 177-205. doi:10.1080/00131911.2011.648371.

Barkley, R.A., Murphy, K., \& Bauermeister, J.J. (1998). El trastorno por déficit de atención e hiperactividad: un manual de trabajo clínico. [Attention deficit disorder and hyperactivity: a clinical wordbook]. New York: Guilford Press.

Bauermeister, J.J., Matos, M., \& Reina, G. (1999). Do the combined and inattentive types of ADHD have a similar impact on family life? ADHD Report, 7, 6-8.

Bauermeister, J.J., \& Cumba, E. (2008). El Inventario de Experiencia Familiar: una medida del impacto de los hijos e hijas en los padres y madres. [The Family Experiences Inventory: a measure of the impact of children on fathers and mothers]. Revista Puertorriqueña de Psicología, 19, 216-222.

Baumrind, D. (1971). Current patterns of parental authority. Child Development, 37, 887-907.

Bilancia, S.D., \& Rescorla, L. (2010). Stability of behavioral and emotional problems over 6 years in children ages 4 to 5 or 6 to 7 at time 1. Journal of Emotional and Behavioral Disorders, 18, 149-161. doi:10.1177/1063426609344865

Bradley, R.H., \& Corwyn, R.F. (2008). Infant temperament, parenting, and externalizing behavior in first grade: A test of the differential susceptibility hypothesis. Journal of Child Psychology and Psychiatry, 49, 124-131.

Brownline, E.B., Beitchman, J.H., Escobar, M., Young, A., Atkinson, L., Johnson, C. et al. (2004). Early language impairment and young adult delinquent and aggressive behavior. Journal of Abnormal Child Psychology, 32, 453-467. doi: 10.1023/B:JACP.0000030297.91759.74

Calero, M.D., Carles, R., Mata, S., \& Navarro, E. (2010). Diferencias en habilidades y conducta entre grupos de preescolares de alto y bajo rendimiento escolar [Differences in skills and behavior between groups of preschoolers with high and low academic performance]. Revista Electrónica de Investigación y Evaluación Educativa. R.E.L.I.E.V.E, 16 (2), 1-17. Accessed from http://www.uv.es/RELIEVE/v16n2/RELIEVEv16n2_5.htm

Calero, M.D., Robles, M.A., Márquez, J., \& de la Osa, P. (2009). EHPAP: Evaluación de habilidades y potencial de aprendizaje en preescolares [Evaluation of abilities and learning potential in preschoolers]. Madrid: EOS. 
Campbell, S.B. (2006). Behavior Problems in Preschool Children: Clinical and Developmental Issues. New York: Guilford Press.

Campbell, S.B., Shaw, D.S., \& Gilliom, M. (2000). Early externalizing behavior problems: Toddlers and preschoolers at risk for later maladjustment. Development and Psychopathology, 12, 467-488. doi: 10.1017/S0954579400003114

Capaldi, D.M., Pears, K.C., Kerr, D.C., \& Owen L.D. (2007). Intergenerational and partner influences on fathers' negative discipline. Journal of Abnormal Child Psychology, 3, 347-358.

Chacko, A., Wakschlag, L., Hill, C., Danis, B., \& Espy, K.A. (2009). Viewing preschool disruptive behaviour disorders and attention-deficit/hyperactivity disorder through a developmental lens: What we know and what we need to know. Child and Adolescent Psychiatric Clinics of North America, 18, 627-643. doi: 10.1016/j.chc.2009.02.003

Del Vecchio, T., \& O'Leary S.G. (2008). Predicting maternal discipline responses to early child aggression: The role of cognitions and affect. Parenting: Science and Practice, 8, 240-256. doi: 10.1080/15295190802204827

Dodge, K.A., Coie, J.D., \& Lynam, D. (2006). Aggression and anti-social behavior. In W. Damon (Series Ed.) \& N. Eisenberg (Vol. Ed.), Handbook of Child Psychology: Vol. 3. Social, emotional, and personality development (pp. 719-788). New York: Wiley.

Egeland, B., Pianta, R., \& Ogawa, J. (1996). Early behavior problems: Pathways to mental disorders in adolescence. Development and Psychopathology, 8, 735-749. doi: $10.1017 / \mathrm{S} 0954579400007392$

Eisenberg, N., Zhou, Q., Spinrad, T.L. Valiente, C., Fabes, A., \& Liew, J. (2005). Relations among positive parenting, children's effortful control, and externalizing problems: A three-wave longitudinal study. Child Development, 76, 1055-1071. doi: 10.1111/j.14678624.2005.00897.x

Fergusson, D.M., Horwood, L.J., \& Ridder, E.M. (2005). Show me the child at seven: The consequences of conduct problems in childhood for psychosocial functioning in adulthood. Journal of Child Psychology and Psychiatry, 46, 837-849. doi: 10.1111/j.14697610.2004.00387.x

Gámez-Guadix, M., Straus, M., Carrobles, J.A., Muñoz-Rivas, M.J., \& Almendros, C. (2010). Corporal punishment and long-term behavior problems: the moderating role of positive parenting and psychological aggression. Psicothema, 22, 529-536. 
Goodman, R. (1997). The Strengths and Difficulties Questionnaire: A research note. Journal of Child Psychology and Psychiatry, 38, 581-586. doi: 10.1111/j.14697610.1997.tb01545.x

Goodman, R. (2001). Psychometric properties of the Strengths and Difficulties Questionnaire. Journal of Child Psychology and Psychiatry, 40, 1337-1345.

Gresham, F.M., \& Elliot, S.N. (1990). Social Skills Rating System: Manual. Circle Pines, Minnesota: American Guidance Service.

Guthermuth-Anthony, L., Anthony, B.J., Glanville, D.N., Naiman, D.Q., Waanders, C., \& Shaffer, S. (2005). The relationships between parenting stress, parenting behaviour and preschoolers' social competence and behaviour problems in the classroom. Infant and Child Development, 14, 133-154. doi: 10.1002/icd.385

Hardaway, C.R., Wilson, M.N., Shaw, D.S., \& Dishion, T.J. (2012). Family functioning and externalizing behaviour among low-income children: self-regulation as a mediator. Infant Child Development, 21, 67-84. doi: 10.1002/icd.765

Harvey, E.A., Youngwirth, S.D., Thakar, D.A., \& Errazuriz, P.A. (2009). Predicting attentiondeficit/hyperactivity disorder and oppositional defiant disorder from preschool diagnostic assessments. Journal of Consulting and Clinical Psychology, 77 (2), 349-354. doi: $10.1037 / \mathrm{a} 0014638$

Juliano, M., Werner, R.B., \& Cassidy, K.W. (2006). Early correlates of preschool aggressive behavior according to type of aggression and measurement. Journal of Applied Developmental Psychology, 27, 395-410. doi: 10.1016/j.appdev.2006.06.008

Juvonen, J., \& Ho, A.Y. (2008). Social motives underlying antisocial behavior across middle school grades. Journal of Youth and Adolescence, 37, 747-756. doi: 10.1007/s10964008-9272-0

Karreman, A., van Tuijl, C., van Aken, M., \& Dekovic, M. (2009). Predicting young children's externalizing problems. Merrill-Palmer Quarterly, 55, 111-134.

Kaufman, A.S., \& Kaufman, A.L. (1994). K- BIT: Test Breve de Inteligencia de Kaufman. Manual de interpretación [K-BIT: Kaufman's Brief Intelligence Test. Interpretation Manual]. Madrid: TEA.

Kochanska, G., Barry, R.A., Aksan, N., \& Boldt, L.J. (2008). A developmental model of maternal and child contributions to disruptive conduct: The first six years. Journal of Child Psychology and Psychiatry, 49, 1220-1227.

Lahey, B.B., Van Hulle, C.A., Rathouz, P.J., Rodgers, J.L., D’onofrio, B.M., \& Waldman, I.D. (2009). Are oppositional-defiant and hyperactive-inattentive symptoms develop- 
mental precursors to conduct problems in late childhood? Genetic and environmental links. Journal of Abnormal Child Psychology, 37, 45-58. doi: 10.1007/s10802-0089257-1

Larzelere, R.E., \& Kuhn, B.R. (2005). Comparing child outcomes of physical punishment and alternative disciplinary tactics: A meta-analysis. Clinical Child and Family Psychology Review, 8, 1-37.

Lengua, L.J. (2006). Growth in temperament and parenting as predictors of adjustment during children's transition to adolescence. Developmental Psychology, 42, 819-832. doi: $10.1037 / 0012-1649.42 .5 .819$

Lidz, C.S., \& Jepsen, R.H. (2003). Application of Cognitive Functions Scale (ACFS): Technical Manual. Unpublished manuscript.

McClelland, M.M., Morrison, F.J., \& Holmes, D.L. (2000). Children at risk for early academic problems: The role of learning-related social skills. Early Childhood Research Quarterly, 15, 307-329. doi: 10.1016/S0885-2006(00)00069-7

Morgan, P.L., Farkas, G., \& Wu, Q. (2009). Kindergarten predictors of recurring externalizing and internalizing psychopathology in the third and fifth grades. Journal of Emotional and Behavioral Disorders, 17, 67-79. doi:10.1177/1063426608324724

Neuenschwander, M.P., Vida, M., Garrett, J.L., \& Eccles, J.S. (2007). Parents’ expectations and students' achievement in two western nations. International Journal of Behavioral Development, 31, 474-482. doi: 10.1177/0165025407080589

Olson, S.L., Sameroff, A.J., Kerr, D.C., Lopez, N.L., \& Wellman, H.M. (2005). Developmental foundations of externalizing problems in young children: The role of effortful control. Development and Psychopathology, 17, 25-45. doi: 10.1017/S0954579405050029

Oudeyer, P.Y., Kaplan, F., \& Hafner, V.V. (2007). Intrinsic motivation systems for autonomous mental development. IEEE Transactions on Evolutionary Computation, Special Issue on Autonomous Mental Development, 11, 265-286. doi: 10.1109/TEVC.2006.890271

Patterson, G.R. (1982). A social learning approach: Vol. 3: Coercive family process. Eugene: Castalia.

Patterson, G.R. (2002). The early development of coercive family process. In J. B. Reid, G. R. Patterson, \& J. Snyder (Eds.), Antisocial behavior in children and adolescents. A developmental analysis and model for intervention (pp. 25-44). Washington: American Psychological Association. 
Rogevich, M.E., \& Perin, D. (2008). Effects on science summarization of a reading comprehension intervention for adolescents with behavior and attention disorders. Exceptional Children, 74, 135-154.

Rubin, K.H., Hemphill, S.A., Chen, X., Hastings, P., Sanson, A., LoCoco, A.,...Doh, H.S. (2006). Parenting beliefs and behaviors: Initial findings from the International Consortium for the Study of Social and Emotional Development (ICSSED). In K.H. Rubin, \& O.B. Chung (Eds.). Parental Beliefs, Parenting, and Child Development in CrossCultural Perspective. (pp. 81-103). London: Psychology Press.

Rutchick, A., Smyth, J.M., Lopoo, M., \& Dusek, J.B. (2009). Great expectations: The biasing effects of reported child behavior problems on educational expectancies and subsequent academic achievement. Journal of Social and Clinical Psychology, 28, 392-413. doi: 10.1521/jscp.2009.28.3.392

Rutter, M., Kim-Cohen, K., \& Maughan, B. (2006). Continuities and discontinuities in psychopathology between childhood and adult life. Journal of Child Psychology and Psychiatry, 47, 276-295. doi: 10.1111/j.1469-7610.2006.01614.x

Smart, D., Prior, M., Sanson, A., \& Oberklaid, F. (2005). Children with reading difficulties: A six year follow-up from early elementary school to adolescence. Australian Journal of Learning Disabilities, 10, 63-76. doi: 10.1080/19404150509546800

Solís, P. (2007). Manual de la Escala de Comportamientos para Madres y Padres con Niños Pequeños (ECMP) [Manual for the Behavior Scale for Mothers and Fathers of Small Children] [Software and manual]. Retrieved from http://www.librosdepsicologia.com

Solís P., Díaz M., Medina Y., Barranco L., Montejano H., \& Tiscareño A. (2002). Estructura factorial y propiedades de la Escala de Comportamientos para Madres y Padres con Niños Pequeños (ECMP) [Factor structure and properties of the Behavior Scale for Mothers and Fathers of Small Children]. Psicothema, 14, 637-642.

Solís, P., Díaz, M., Cortés, N.C., Patiño, D., Pérez, T., \& Robles, C. (2005). Propiedades psicométricas de la Escala de Comportamientos para Madres y Padres con Niños Pequeños [Psychometric properties of the Behavior Scale for Mothers and Fathers of Small Children]. Revista Latinoamericana de Psicología, 37, 59-69.

Solís, R., Díaz, M., del Carpio, P., Esquivel, E., Acosta, I., \& de Jesús, A. (2007). La contribución del bienestar subjetivo, las expectativas y la crianza maternas en los logros escolares de sus niños y en la valoración de la participación de los padres [Contribution of mothers' subjective well-being, expectations and parenting in children's school achie- 
vement and in the assessment of parenting involvement]. Acta Colombiana de Psicología, 10, 71-82.

Stith, S.M., Liu, T., Davies, C., Boykin, E.L., Alder, M.C., Harris, J.M., ... Dees, J.E. (2009). Risk factors in child maltreatment: A meta-analytic review of the literature. Aggression and Violent Behavior, 14, 13-29. doi: 10.1016/j.avb.2006.03.006

Trentacosta, C.J., Hyde, L.W., Shaw, D.S., Dishion, T.J., Gardner, F., \& Wilson, M. (2008). The relations among cumulative risk, parenting, and behavior problems during early childhood. Journal of Child Psychology and Psychiatry, 49, 1211-1219.

Trosper, S., Buzzella, B., Bennett, S., \& Ehrenreich, J. (2009). Emotion regulation in youth with emotional disorders: Implications for a unified treatment approach. Clinical Child and Family Psychology Review, 12, 234-254. doi: 10.1007/s10567-009-0043-6

Wakschlag, L.S., Leventhal, B.L., Briggs-Gowan, M.J., Danis, B., Keenan, K., Hill, ... Carter, A.S. (2005). Defining the "disruptive" in preschool behavior: What diagnostic observation can teach us. Clinical Child and Family Psychology Review, 8, 183-201. doi: 10.1007/s10567-005-6664-5

Webster-Stratton, C., \& Taylor, T. (2001). Nipping early risk factors in the bud: Preventing substance abuse, delinquency, and violence in adolescence through interventions targeted at young children (0-8 years). Prevention Science, 2, 165-192. doi: 10.1023/A:1011510923900 